\title{
Influence of Ammonium Salt and Fermentation pH on Acarbose Yield from Streptomyces M37
}

\author{
Fei Ren ${ }^{1,2}$, Long Chen ${ }^{1}$ and Qunyi Tong ${ }^{3 *}$ \\ ${ }^{1}$ State Key Laboratory of Food Science and Technology, Jiangnan University, Wuxi, Jiangsu, 214122, ${ }^{2}$ College of Life Science \\ and Technology, Southwest University of Science and Technology, Mianyang, Sichuan, 621010, ${ }^{3}$ School of Food Science and \\ Technology, Jiangnan University, 1800 Lihu Road, Wuxi, Jiangsu 214122, China
}

*For correspondence: Email: qytong@263.net; Tel: +86 510 85919170; Fax: +86 51085919170

Received: 6 August 2014

Revised accepted: 8 November 2014

\begin{abstract}
Purpose: To investigate the effect of ammonium salts and fermentation $\mathrm{pH}$ on the biosynthesis of acarbose by Streptomyces M37.

Methods: Different ammonium salts were added to the fermentation broth of Streptomyces M37 to explore their effects on acarbose production. The concentration and addition time of ammonium salts, and the fermentation $\mathrm{pH}$ on acarbose biosynthesis were investigated. To study the effect of $\mathrm{pH}$ on acarbose yield, the activities of glutamate dehydrogenase (GDH) and glucose-6-phosphate dehydrogenase (G6PDH) were also studied.

Results: The optimal supplemental concentration and addition time of $\mathrm{NH} 4 \mathrm{Cl}$ were $0.1 \mathrm{M}$ and $72 \mathrm{~h}$, respectively. Regulation of $\mathrm{pH}$ at 8.5 until the stationary phase was reached favoured acarbose production. Furthermore, GDH and G6PDH exhibited higher activity at pH 8.5 than at other pHs. Increase in acarbose yield was $53.4 \%$ (compared with control) by NH4Cl, and was approximately 5460 $\mathrm{mg} / \mathrm{L}$.

Conclusion: The results suggest that the addition of $\mathrm{NH} 4 \mathrm{Cl}$ and maintenance of fermentation $\mathrm{pH}$ at 8.5 for $72 \mathrm{~h}$ after inoculation was an effective strategy for enhancing acarbose biosynthesis.
\end{abstract}

Keywords: Acarbose, Ammonium salts, pH, Streptomyces, Glutamate dehydrogenase, Glucose-6phosphate dehydrogenase, Biosynthesis, Fermentation

Tropical Journal of Pharmaceutical Research is indexed by Science Citation Index (SciSearch), Scopus, International Pharmaceutical Abstract, Chemical Abstracts, Embase, Index Copernicus, EBSCO, African Index Medicus, JournalSeek, Journal Citation Reports/Science Edition, Directory of Open Access Journals (DOAJ), African Journal Online, Bioline International, Open-J-Gate and Pharmacy Abstracts

\section{INTRODUCTION}

Diabetes mellitus is a chronic disease caused by inherited and/or acquired deficiency in production of insulin by the pancreas, or by the ineffectiveness of the insulin produced. If it is not controlled, diabetes can lead to serious chronic complications in the eyes, kidneys, peripheral nerve system and arteries, and result in impaired quality of life, disability and mortality [1].

As a competitive a-glucosidase inhibitor, acarbose is widely used in the therapy of non- insulin-dependent diabetes mellitus owing to its good therapeutic and non-toxic effects $[2,3]$.

Acarbose, composed of an aminocyclitol and valienamine linked via a nitrogen bridge to $\mathrm{C}-4$ of 6-deoxy-D-glucose, is produced by strains of the genus Actinoplanes [4]. Many aspects of acarbose fermentation have been well studied and reported, ranging from producer strains, media formula, fermentation conditions, and acarbose isolation and purification [5-9]. The importance of nitrogen sources in industrial microbiology is very significant since it affects the 
synthesis of enzymes involved in both primary and secondary metabolism [10-12]. It is known that glutamate is the primary source of $\mathrm{N}$ glycosidic bond in the biosynthesis of acarbose [13]. Wang et al [7] found that raising monosodium glutamate (MG) concentration up to $5 \mathrm{~g} / \mathrm{L}$ promoted acarbose production with $A$. utahensis ZJB-08196. However, the effects of inorganic nitrogen source and $\mathrm{pH}$ on acarbose fermentation have not been reported thus far.

In this study, the effect of concentration of $\mathrm{NH} 4 \mathrm{Cl}$ and its addition time on the biosynthesis of acarbose by Streptomyces M37 were determined. The impact of fermentation $\mathrm{pH}$ and the activities of glutamate dehydrogenase (GDH) and glucose-6-phosphate dehydrogenase (G6PDH) on arcabose yield were also investigated.

\section{EXPERIMENTAL}

\section{Microorganism}

Streptomyces M37 (GenBank KJ888155) with high acarbose yield was isolated and mutated in our laboratory and used for acarbose production. The strain was maintained in a $20 \%(\mathrm{v} / \mathrm{v})$ sterile glycerol stock solution and stored at $-80{ }^{\circ} \mathrm{C}$. Before carrying out the study, Streptomyces M37 was activated on agar plates at $28^{\circ} \mathrm{C}$ for about 6 days until visible pink colonies emerged. The components (in $\mathrm{g} / \mathrm{L}$ ) of agar medium were: sucrose, 20; $\mathrm{K}_{2} \mathrm{HPO}_{4} \cdot 3 \mathrm{H}_{2} \mathrm{O}, 1.0 ; \mathrm{FeSO}_{4} \cdot 7 \mathrm{H}_{2} \mathrm{O}$, $0.02 ; \mathrm{MgSO}_{4}, 1.0 ; \mathrm{NaNO}_{3}, 2.0$; peptone, 1.0; agar, 20. Unless otherwise stated, the initial $\mathrm{pH}$ value of all media was adjusted to 7.4 with $1 \mathrm{M}$ $\mathrm{NaOH}$ prior to sterilization, and all media were sterilized by steam autoclaving at $121{ }^{\circ} \mathrm{C}$ for 20 min.

\section{Medium and culture conditions}

For inoculation, a colony of about $1 \times 1 \mathrm{~cm}^{2}$ from a freshly prepared agar plate was inoculated into a $500 \mathrm{~mL}$ Erlenmeyer flask containing $100 \mathrm{ml}$ of seed medium and cultivated at $28^{\circ} \mathrm{C}, 200 \mathrm{rpm}$ for $72 \mathrm{~h}$. The seed cultures for the fermentation inoculum were prepared by medium which consisted of the following in (in $\mathrm{g} / \mathrm{L}$ ) starch, 15; glucose, 20; soybean meal, 15; peptone, 2.0; yeast extract, $1.0 ; \mathrm{K}_{2} \mathrm{HPO}_{4} \cdot 3 \mathrm{H}_{2} \mathrm{O}, 1.0 ; \mathrm{MgSO}_{4}$, 1.0; $\mathrm{CaCO}_{3}, 3.0$.

\section{Acarbose fermentation}

Batch and fed-batch fermentation was carried out in $500 \mathrm{~mL}$ Erlenmeyer flasks. A $10.0 \mathrm{~mL}$ of seed culture was used to inoculate $90 \mathrm{~mL}$ of fermentation medium. Batch fermentation was carried out at $28^{\circ} \mathrm{C}$ and $200 \mathrm{rpm}$ for 7 days, in a medium which contained (in $\mathrm{g} / \mathrm{L}$ ): sucrose, 30 ; maltose, 25; soybean meal, 20; peptone, 2.0; yeast extract, $1.0 ; \mathrm{NaNO}_{3}, 1.0 ; \mathrm{K}_{2} \mathrm{HPO}_{4} \cdot 3 \mathrm{H}_{2} \mathrm{O}$, 1.5; $\mathrm{MgSO}_{4}, 1.0 ; \mathrm{FeSO}_{4} \cdot 7 \mathrm{H}_{2} \mathrm{O}, 0.03$; and $\mathrm{CaCO}_{3}$, 3.0 .

After $72 \mathrm{~h}$ of cultivation, MG or ammonium salts $\left(\mathrm{NH}_{4} \mathrm{Cl},\left(\mathrm{NH}_{4}\right)_{2} \mathrm{SO}_{4}\right.$ and $\left.\mathrm{NH}_{4} \mathrm{NO}_{3}\right)$ were added separately in the cultivation medium. According to results of our preliminary experiments, ammonium salt containing $0.1 \mathrm{M}$ of $\mathrm{NH}_{4}{ }^{+}$was added to the fermentation medium at different cultivation times: $48,72,96$ and $120 \mathrm{~h}$.

The experiment to investigate the effect of different concentrations of $\mathrm{NH}_{4} \mathrm{Cl}$ on acarbose production was carried out at initial $\mathrm{pH}$ of 7.4. After the addition of $0.1 \mathrm{M} \mathrm{NH}_{4} \mathrm{Cl}$ at $72 \mathrm{~h}$, the $\mathrm{pH}$ was adjusted to 7.0 with $2 \mathrm{M} \mathrm{NaOH}$. The experiment on the effect of different $\mathrm{pH}$ values (ranging from 6.0 to 10.0) on acarbose production was carried out in $5 \mathrm{~L}$ fermentor with a working volume of $3.0 \mathrm{~L}$. The fermentation temperature was $28^{\circ} \mathrm{C}$ and the impeller speed was set at $150 \mathrm{rpm}$ with the aeration rate of 1 $\mathrm{vol} / \mathrm{min}$. The $\mathrm{pH}$ was maintained stable at required values according to the experimental need during the fermentations with $2 \mathrm{M} \mathrm{HCl}$ or 2 $\mathrm{M} \mathrm{NaOH}$.

\section{Analytical methods}

The mycelia were harvested by centrifugation ( 10 min, at $9,000 \times \mathrm{g}$ ) and suspended in $10 \mathrm{~mL}$ of 10 $\mathrm{mM}$ potassium phosphate buffer $(\mathrm{pH}$ 7.2) containing $2 \mathrm{mM}$ ethylene diamine tetraacetic acid (EDTA) and $2 \mathrm{mM}$ dithiothreitol (DTT). The mycelia were sonicated on ice for $15 \mathrm{~min}$ and cell debris was removed by centrifugation $(9000 \times \mathrm{g})$ for $30 \mathrm{~min}$ at $4{ }^{\circ} \mathrm{C}$. The supernatant was used as crude enzyme for measuring GDH activity.

Reductive GDH activity was measured spectrophotometrically at $30{ }^{\circ} \mathrm{C}$ by monitoring the oxidation of NADH or NADPH at $340 \mathrm{~nm}$. The $3 \mathrm{~mL}$ reaction mixture contained $13 \mathrm{mM} 2-$ oxoglutarate, $1.7 \mathrm{mM}$ NADH or NADPH. $15 \mathrm{mM}$ $\mathrm{NH}_{4} \mathrm{Cl}, 15 \mathrm{mM} \mathrm{NH}_{3} \cdot \mathrm{H}_{2} \mathrm{O}$, or $7.5 \mathrm{mM}\left(\mathrm{NH}_{4}\right)_{2} \mathrm{SO}_{4}$ was added separately for the reductive $\mathrm{GDH}$ activity. Reactions were started by adding the enzyme. One unit of activity was defined as the amount of enzyme catalyzing the oxidation of 1 $\mu$ mole of the substrate per min at $30{ }^{\circ} \mathrm{C}$. Protein was measured by the method of Bradford using bovine serum albumin (Sigma) as a standard [14]. G6PDH was detected according to Ruijter [15].

Trop J Pharm Res, December 2014; 13(12): 2076 
The dry cell weight (DCW) was determined according to Wang et al [8]. $\mathrm{pH}$ was determined by using a $\mathrm{pH}$ meter. Glucose was estimated with a SBA-40E biosensor (Shangdong, China). Maltose was determined by ion chromatography according to Xue et al [16]. Acarbose titer was analyzed by HPLC according to $\mathrm{Li}$ et al [5]. $\mathrm{NH}_{4}{ }^{+}-$ $\mathrm{N}$ was determined according to Mulder et al [17].

\section{Statistical analysis}

All experiments were performed in triplicate. One-way analysis of variance (ANOVA) was performed to determine significant differences among variables. Differences with a probability value of $<0.05$ were considered significant and all data were reported as mean \pm SD. Statgraphics Centurion XV program (version 15.1.02) was used.

\section{RESULTS}

\section{Effect of time on acarbose fermentation}

The time course studies on acarbose yield by Streptomyces M37 were carried out for a period of $168 \mathrm{~h}$ in the fermentation media, as shown in Figure 1. After $24 \mathrm{~h}$ of lag phase, Streptomyces M37 entered the exponential growth phase and reached the maximum DCW of $21.5 \mathrm{~g} / \mathrm{L}$ at $72 \mathrm{~h}$. The microorganism entered stationary phases after $72 \mathrm{~h}$ cultivation. Acarbose production increased significantly to the maximum of 3560 $\mathrm{mg} / \mathrm{L}$ within $120 \mathrm{~h}$ and tended to be stable afterwards. The $\mathrm{pH}$ value of the fermentation broth decreased to 5.9 after $96 \mathrm{~h}$ of cultivation. The $\mathrm{pH}$ value decreased to 5.9 after $96 \mathrm{~h}$ during the fermentation. And the final $\mathrm{pH}$ was lower than 5.6. Actinomycetes prefer to grow under alkaline environment. For this reason, the acidic environment is not conducive to actinomyces growth and synthesis of metabolites. Wang et al. reported the $\mathrm{pH}$ varied in a narrow range between 6.0 and 8.0 throughout the fed-batch fermentation during acarbose production with Actinoplanes utahensis ZJB-08196 [8]. Therefore, it was likely that the biosynthesis of acarbose was inhibited by the lower fermentation $\mathrm{pH}$.

\section{Effect of various ammonium salts on acarbose production}

The concentrations of the various salts were optimized separately through single factor experiment in our pilot studies (data not shown). The suitable addition concentration of ammonium salts was shown in Table 1 . With the addition of $0.1 \mathrm{M} \mathrm{NH}_{4} \mathrm{Cl}$, the acarbose yield reached 4875 $\mathrm{mg} / \mathrm{L}$. The result showed that $\mathrm{NH}_{4} \mathrm{Cl}$ exhibited better promoting effect than other ammonium salts and MG.

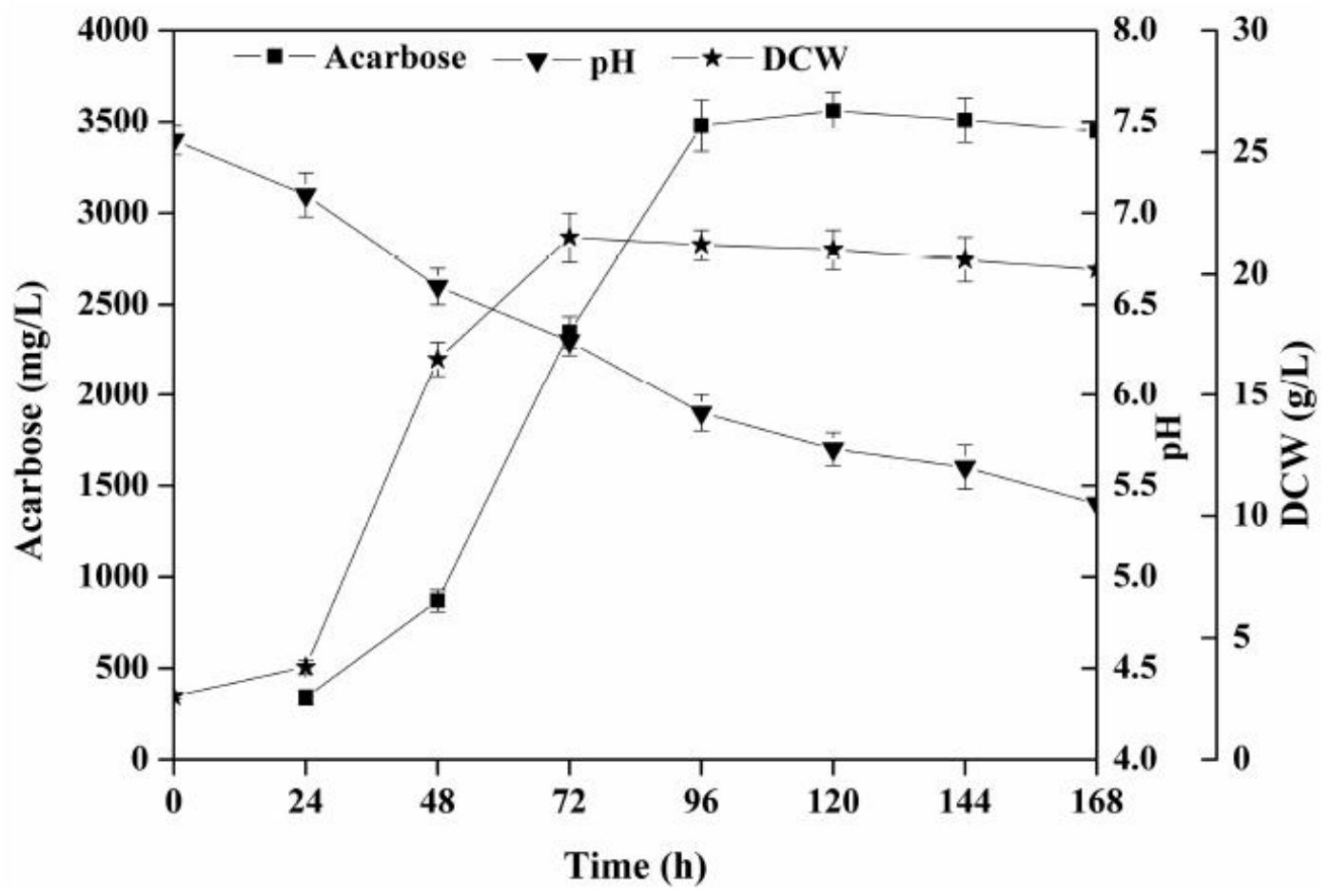

Figure 1: Effect of time on acarbose fermentation. Bars represent the standard deviation. Data are shown as mean $\pm S D(n=3)$ 
To investigate the possible effect of $\mathrm{Cl}^{-}$on acarbose formation, $0.1 \mathrm{M} \mathrm{NaCl}$ was added to the fermentation broth, and the biomass concentration and acarbose yield were found unaffected (data not shown). Hence, the influence of $\mathrm{Cl}^{-}$on acarbose biosynthesis was excluded.

\section{Effect of addition time of $\mathrm{NH} 4 \mathrm{Cl}$ on acarbose production}

The effects of the addition time of $\mathrm{NH}_{4} \mathrm{Cl}$ on biomass and acarbose yield are shown in Table 2. $\mathrm{NH}_{4} \mathrm{Cl}(0.1 \mathrm{M})$ was added to the fermentation broths in different fermentation stages: $48 \mathrm{~h}, 72$ h, $96 \mathrm{~h}$, and $120 \mathrm{~h}$. For cell growth, when $\mathrm{NH}_{4} \mathrm{Cl}$ was added at $48 \mathrm{~h}$ (log phase), the DCW increased about $10 \%$. There was an obvious increase in acarbose production when $\mathrm{NH}_{4} \mathrm{Cl}$ was added to the fermentation broths at all of the above times. Notably, when $\mathrm{NH}_{4} \mathrm{Cl}$ was added at $72 \mathrm{~h}$, the highest acarbose yield (4875 mg/L) was obtained. Therefore, $72 \mathrm{~h}$ was chosen as the optimal addition time.

\section{Effect of concentration of $\mathrm{NH}_{4} \mathrm{CL}$ on arcabose yield}

As shown in Table 3, acarbose yield was significantly affected by the concentrations of $\mathrm{NH}_{4} \mathrm{Cl}$. The highest acarbose yield was achieved when $0.1 \mathrm{M} \mathrm{NH} \mathrm{NH}_{4} \mathrm{Cl}$ was added to the fermentation broth. Results in Table 2 and Table 3 demonstrate that the optimal addition concentration and time were $0.1 \mathrm{M}$ and $72 \mathrm{~h}$. In addition, more than $30 \%$ of the initial glucose $(10.0 \mathrm{~g} / \mathrm{L})$ and maltose $(8.0 \mathrm{~g} / \mathrm{L})$ remained in the culture medium at the end of all the fermentations, thus ensuring enough supply of carbon sources and precursors for cell growth and acarbose formation.

\section{Impact of pH on acarbose production}

The $\mathrm{pH}$ was one of the important fermentation parameters affecting cell growth and product formation [5]. Actively growing microorganisms acidified their medium through a combination of differential ion uptake,

Table 1: Effect of addition of different ammonium salts or monosodium glutamate on DCW, $\mathrm{pH}$ and acarbose yield at $168 \mathrm{~h}$

\begin{tabular}{lccc}
\hline Cultivation conditions $^{\text {a }}$ & DCW(g/L) & Final pH & Acarbose (mg/L) \\
\hline Control & $20.2 \pm 0.5$ & $5.50 \pm 0.11$ & $3560 \pm 105$ \\
$0.1 \mathrm{M} \mathrm{monosodium}$ glutamate & $20.4 \pm 0.8$ & $6.41 \pm 0.05$ & $3980 \pm 124$ \\
$0.1 \mathrm{M} \mathrm{NH} \mathrm{Ml}_{4} \mathrm{M} \mathrm{NH} \mathrm{NO}_{3}$ & $21.3 \pm 0.7$ & $6.34 \pm 0.10$ & $4875 \pm 146$ \\
$0.1 \mathrm{M}\left(\mathrm{NH}_{4}\right)_{2} \mathrm{SO}_{4}$ & $21.0 \pm 1.0$ & $6.40 \pm 0.06$ & $4760 \pm 130$ \\
$0.05 \mathrm{M}_{4}$ & $20.8 \pm 0.9$ & $6.26 \pm 0.10$ & $4650 \pm 112$ \\
\hline
\end{tabular}

${ }^{a}$ Monosodium glutamate and ammonium salts were added at $72 \mathrm{~h}$ after inoculation with the $\mathrm{pH}$ adjusted to 7.0 using $2 \mathrm{M} \mathrm{NaOH}$. Data are shown as mean $\pm S D(n=3)$

Table 2: Effect of addition time of $\mathrm{NH}_{4} \mathrm{Cl}$ on $\mathrm{DCW}$, final $\mathrm{pH}$ and acarbose yield at $168 \mathrm{~h}$

\begin{tabular}{lccc}
\hline${\text { Addition time }(\mathbf{h})^{\text {a }}}$ & $\mathbf{D C W}(\mathbf{g} / \mathbf{L})$ & Final $\mathbf{~ p H}$ & Acarbose $(\mathbf{m g} / \mathbf{L})$ \\
\hline Control & $20.2 \pm 1.1$ & $5.50 \pm 0.11$ & $3560 \pm 102$ \\
48 & $22.4 \pm 0.6$ & $6.14 \pm 0.10$ & $3580 \pm 105$ \\
72 & $21.2 \pm 1.0$ & $6.38 \pm 0.08$ & $4875 \pm 128$ \\
96 & $20.3 \pm 1.2$ & $6.42 \pm 0.12$ & $4690 \pm 115$ \\
120 & $19.8 \pm 1.2$ & $6.46 \pm 0.10$ & $4330 \pm 104$ \\
\hline${ }^{a}$ The addition concentration of $\mathrm{NH}_{4} \mathrm{Cl}$ was $0.1 \mathrm{M} ; \mathrm{pH}$ was adjusted to 7.0 with $2 \mathrm{M} \mathrm{NaOH}$ after addition of $\mathrm{NH}_{4} \mathrm{Cl}$. \\
\multicolumn{2}{l}{ Data are shown as mean $\pm \mathrm{SD}(n=3)$}
\end{tabular}

Table 3: Effect of addition concentrations of $\mathrm{NH}_{4} \mathrm{Cl}$ on DCW, $\mathrm{pH}$ and acarbose yield at $168 \mathrm{~h}$

\begin{tabular}{cccc}
\hline Cultivation conditions $^{{ }^{a}}$ & DCW(g/L) & Final pH & Acarbose (mg/L) \\
\hline Control $_{0.06 \mathrm{M}^{\mathrm{a}}}$ & $20.2 \pm 1.1$ & $5.50 \pm 0.10$ & $3463 \pm 120$ \\
$0.08 \mathrm{M}$ & $20.4 \pm 0.9$ & $6.47 \pm 0.10$ & $3980 \pm 105$ \\
$0.10 \mathrm{M}$ & $20.7 \pm 1.1$ & $6.45 \pm 0.08$ & $4390 \pm 120$ \\
$0.12 \mathrm{M}$ & $21.2 \pm 1.0$ & $6.40 \pm 0.07$ & $4875 \pm 125$ \\
$0.14 \mathrm{M}$ & $20.7 \pm 1.2$ & $6.36 \pm 0.10$ & $4630 \pm 96$ \\
\hline
\end{tabular}

${ }^{a} \mathrm{NH}_{4} \mathrm{Cl}$ was added at $72 \mathrm{~h}$ after inoculation. The $\mathrm{pH}$ was adjusted to 7.0 with $2 \mathrm{M} \mathrm{NaOH}$ after the addition of $\mathrm{NH}_{4} \mathrm{Cl}$. Data are shown as mean $\pm \mathrm{SD}(n=3)$ 
proton secretion during nutrient transport, direct secretion of organic acids, and $\mathrm{CO}_{2}$ evolution [18]. As shown in Table 2 and Table 3, decrease of the medium $\mathrm{pH}$ was observed. This might be due to the transport of ammonium leading to acidify of the extracellular medium [19]. It was reported that controlling the $\mathrm{pH}$ of the culture medium increased the biomass and polysaccharide production [20]. Therefore, it was of great importance to control the fermentation $\mathrm{pH}$ for acarbose biosynthesis.

Effect of $\mathrm{pH}$ on acarbose yield was investigated by controlling the medium $\mathrm{pH}$ between 6.0 and 10.0 in $5 \mathrm{~L}$ fermentor. According to the results presented in Figure 2 and Figure 3, acarbose yield continuously increased from $72 \mathrm{~h}$ to $168 \mathrm{~h}$ with decreases in $\mathrm{NH}_{4}{ }^{+}-\mathrm{N}$. Acarbose increased

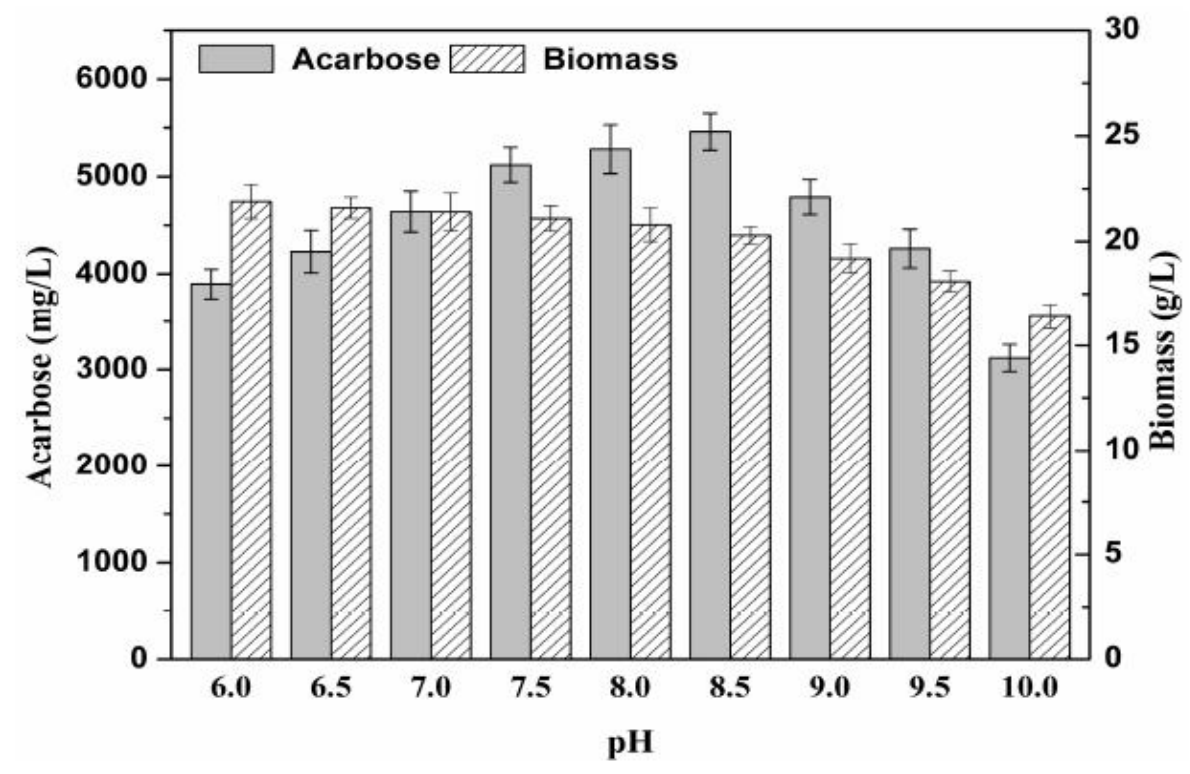

Figure 2: Effect of $\mathrm{pH}$ on acarbose yield during Streptomyces $\mathrm{M} 37$ fermentation. Experiments were carried out in $5 \mathrm{~L}$ fermentor. $\mathrm{NH}_{4} \mathrm{Cl}(0.1 \mathrm{M})$ was added at $72 \mathrm{~h}$ after inoculation. $\mathrm{pH}$ was controlled with $2 \mathrm{M} \mathrm{NaOH}$ and $2 \mathrm{M} \mathrm{HCl}$ since the addition of $\mathrm{NH}_{4} \mathrm{Cl}$. Bars represent the standard deviation $(n=3)$. Data are shown as mean $\pm \mathrm{SD}(n=3)$

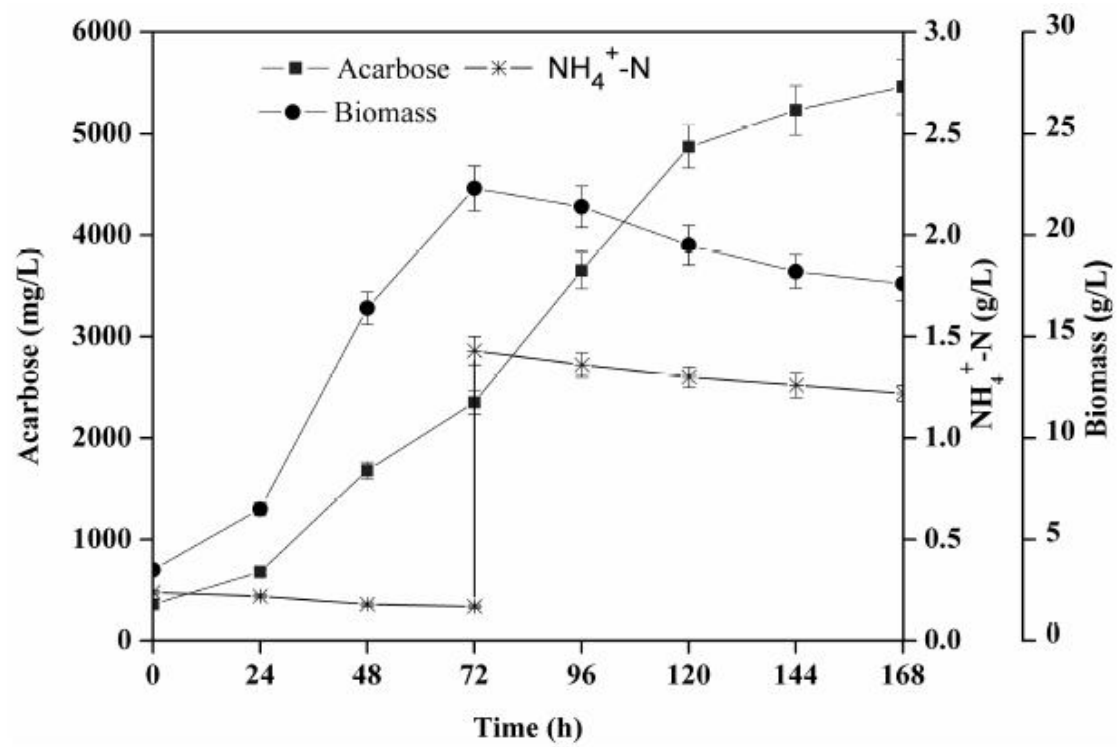

Figure 3: Time course of acarbose titer, biomass and $\mathrm{NH}_{4}{ }^{+}-\mathrm{N}$ during fed-batch cultivation of with an optimized feeding strategy. Experiments were carried out in $5 \mathrm{~L}$ fermentor. $\mathrm{NH}_{4} \mathrm{Cl}(0.1 \mathrm{M})$ was added at $72 \mathrm{~h}$ after inoculation. $\mathrm{pH}$ was controlled at 8.5 with $2 \mathrm{M} \mathrm{NaOH}$ and $2 \mathrm{M} \mathrm{HCl}$ since the addition of $\mathrm{NH}_{4} \mathrm{Cl}$. Bars represent the standard deviation. Data are shown as mean $\pm \operatorname{SD}(n=3)$ 
obviously in the $\mathrm{pH}$ range of 6.0 - 9.5. A maximum acarbose yield of $5460 \mathrm{mg} / \mathrm{L}$ was obtained at $\mathrm{pH} 8.5$, which was increased by 53.4 $\%$ when compared with the control. However, when the $\mathrm{pH}$ was higher than 9.5, the acarbose yield decreased. It was probably due to the alkaline environment inhibits the enzymes involved in acarbose biosynthesis. Therefore, it was necessary to control the fermentation $\mathrm{pH}$ at 8.5 since $72 \mathrm{~h}$ after inoculation.

\section{Effect of fermentation pH on GDH and G6PDH activities}

GDH are widely distributed enzymes that link carbon and nitrogen metabolism [21]. The physiological role of GDH might be anabolic and/or catabolic. Moreover, biosynthesis studies revealed that the cyclitol moieties of acarbose and validamycin were derived from the HMP pathway, presumably via sedoheptulose 7phophate or ido-heptulose 7-phosphate as intermediate $[13,22]$. G6PDH is the key enzyme of HMP pathway. The activities of GDH and G6PDH might affect acarbose fermentation by Streptomyces M37.

The impact of $\mathrm{pH}$ on the activity of GDH and G6PDH was shown in Figure 4. GDH and G6PDH exhibited the highest level of enzyme activities at pH 8.5. Higher enzyme activity might stimulate Streptomyces M37 to produce more glutamate and sedoheptulose 7-phophate for acarbose synthesis during the fermentation process. Using inorganic nitrogen $\left(\mathrm{NH}_{4} \mathrm{Cl}\right)$ and controlling the $\mathrm{pH}$ during acarbose fermentation can significantly lower the production cost of acarbose.

\section{DISCUSSION}

There is no consensus in the fermentation literature concerning the influence of ammonium on aminoglycoside productivity. Some studies reported that ammonium impedes aminoglycoside synthesis, whereas others revealed stimulatory effects. Some reports have shown that addition of ammonium to the culture medium enhanced streptomycin and other aminoglycoside processes such as neomycin and gentamicin production [23,24]. Ammonium stimulated acarbose formation probably due to the direct requirement of Streptomyces M37 for exogenous glutamate was not so strict, attributing to other sources available from in vivo anabolic pathway like transamination. Similar conclusion was achieved in gentamicin and streptomycin biosynthesis. That is, glutamate, glutamine and glucosamine stimulated the formation of antibiotics containing aminoglycoside group [25].

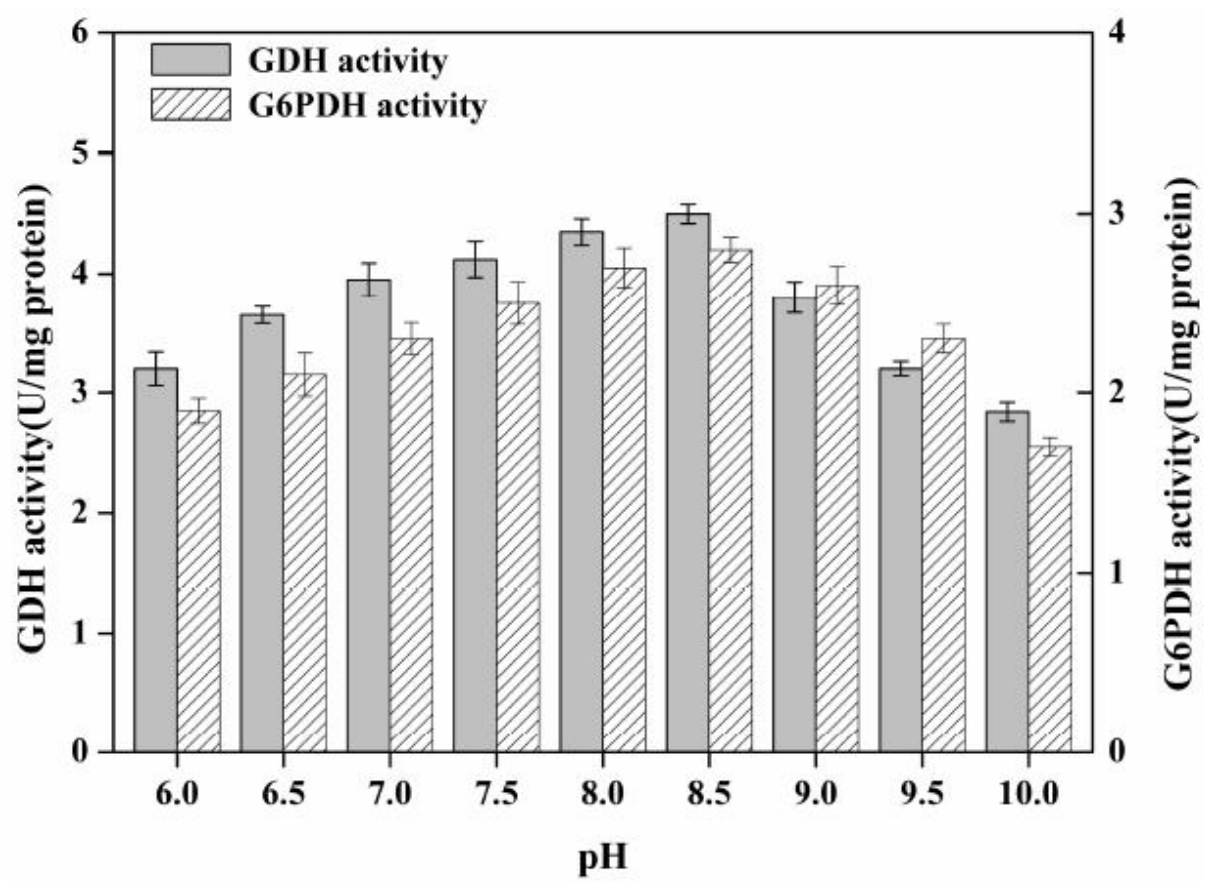

Figure 4: $\mathrm{GDH}$ and G6PDH activities at different $\mathrm{pH}$ values. Experiments were carried out in $5 \mathrm{~L}$ fermentor. $\mathrm{NH}_{4} \mathrm{Cl}(0.1 \mathrm{M})$ was added at $72 \mathrm{~h}$ after inoculation. $\mathrm{pH}$ was controlled with $2 \mathrm{M} \mathrm{NaOH}$ and $2 \mathrm{M} \mathrm{HCl}$ since the addition of $\mathrm{NH}_{4} \mathrm{Cl}$. The enzyme activities were measured at $120 \mathrm{~h}$. Bars represent the standard deviation. Data are shown as mean $\pm S D(n=3)$ 
Medium pH affects enzyme synthesis, enzymatic processes, and transport across cell membranes [7]. The concentration of ammonia was primarily determined by the ammonium concentration, but under increasing $\mathrm{pH}$ the fraction of nitrogen in the form of ammonia increased. Ammonia is generally toxic to microbes, as it was uncharged and could pass through cell membrane [26,27]. In our study, the alkaline stress ( $\mathrm{pH}$ 8.5) accelerated Streptomyces M37 consuming ammonia and producing acarbose, as a strategy to attenuate alkalinization of the cytoplasm. Inhibitory action on hydrolases was one of the functions of acarbose [28]. In the present research, the results demonstrated that alkaline environment stimulated Streptomyces M37 to synthesis acarbose thus relieving the poison of ammonia and facilitating its survival.

\section{CONCLUSION}

The results indicate that acarbose yield is significantly increased by a supplement of $0.1 \mathrm{M}$ $\mathrm{NH}_{4} \mathrm{Cl}$ at $72 \mathrm{~h}$ while maintaining $\mathrm{pH}$ at 8.5. Furthermore, addition $\mathrm{NH}_{4} \mathrm{Cl}$ to the medium also enhances the activities of $\mathrm{GDH}$ and G6PDH, probably due to stimulation of transamination in cells by ammonium to form glutamate. Glutamate can be used to synthesize acarbose from glucose and maltose, thus minimizing the harmfulness of ammonia. The strategy proposed in this work is potentially applicable to fermentation of secondary metabolites containing the aminoglycoside group.

\section{ACKNOWLEDGEMENT}

This work was financially supported by the Priority Academic Program Development of Jiangsu Higher Education Institutions, China.

\section{REFERENCES}

1. Yang W, Lu J, Weng J, Jia W, Ji L, Xiao J, Shan Z, Liu J, Tian $H$, Ji Q. Prevalence of diabetes among men and women in China. N Engl J Med 2010; 362: 10901101.

2. Schnell O, Mertes G, Standl E. Acarbose and metabolic control in patients with type 2 diabetes with newly initiated insulin therapy. Diabetes Obes Metab 2007; 9: 853-858.

3. Wehmeier UF, Piepersberg W. Biotechnology and molecular biology of the alpha-glucosidase inhibitor acarbose. Appl Microbiol Biotechnol 2004; 63: 613625.

4. Mahmud T. The $C 7 N$ aminocyclitol family of natural products. Nat Prod Rep 2003; 20: 137-166.
5. Li K, Zhou J, Wei S, Cheng X. An optimized industrial fermentation processes for acarbose production by Actinoplanes sp. A56. Bioresource Technol 2012; 118: $580-583$.

6. Sun $L H$, Li MG, Wang YS, Zheng YG. Significantly Enhanced Production of Acarbose in Fed-Batch Fermentation with the Addition of SAdenosylmethionine. J Microbiol Biotechnol 2012; 22: 826-831.

7. Wang YJ, Liu LL, Feng ZH, Liu ZQ, Zheng YG. Optimization of media composition and culture conditions for acarbose production by Actinoplanes utahensis ZJB-08196. World J Microbiol Biotechnol 2011; 27: 2759-2766.

8. Wang YJ, Liu LL, Wang YS, Xue YP, Zheng YG, Shen YC. Actinoplanes utahensis ZJB-08196 fed-batch fermentation at elevated osmolality for enhancing acarbose production. Bioresource Technol 2012; 103: 337-342.

9. Xue YP, Qin JW, Wang YJ, Wang YS, Zheng YG. Enhanced Production of Acarbose and Concurrently Reduced Formation of Impurity $C$ by Addition of Validamine in Fermentation of Actinoplanes utahensis ZJB-08196. Biomed Res Int 2013; 705418.

10. Merrick M, Edwards R. Nitrogen control in bacteria. Microbiol Rev 1995; 59: 604-622.

11. Shapiro S. Nitrogen assimilation in actinomycetes and the influence of nitrogen nutrition on actinomycete secondary metabolism. Regulation of secondary metabolism in actinomycetes, 1989; 135-211.

12. Wei ZH, Bai L, Deng Z, Zhong JJ. Impact of nitrogen concentration on validamycin $A$ production and related gene transcription in fermentation of Streptomyces hygroscopicus 5008. Bioproc Biosyst Eng 2012; 35: 1201-1208.

13. Lee S, Egelkrout E. Biosynthetic studies on the alphaglucosidase inhibitor acarbose in Actinoplanes sp.: Glutamate is the primary source of the nitrogen in acarbose. J Antibiot 1998; 51: 225-227.

14. Bradford MM. A rapid and sensitive method for the quantitation of microgram quantities of protein utilizing the principle of protein dye binding. Anal Biochem 1976; 72: 248-254.

15. Ruijter G, Panneman H, Visser J. Overexpression of phosphofructokinase and pyruvate kinase in citric acid-producing Aspergillus niger. BBA-Gen Subjects 1997; 1334: 317-326.

16. Xue $X$, Zhao J, Chen L, Wu L, Zhou J, Li R, Li Y. Determination of sugars in bee pollen and royal jelly by ion chromatography. Food Fermn Ind (Chinese) 2012; 38: 162-165.

17. Mulder A, Graaf A, Robertson L, Kuenen J. Anaerobic ammonium oxidation discovered in a denitrifying fluidized bed reactor. FEMS Microbiol Ecol 1995; 16 : 177-184.

18. Walker GM. Yeast physiology and biotechnology. John Wiley \& Sons 1998. 
19. Wang K, Mao Z, Zhang C, Zhang J, Zhang H, Tang L. Influence of nitrogen sources on ethanol fermentation in an integrated ethanol-methane fermentation system. Bioresource Technol 2012; 120: 206-211.

20. Li H, Li J, Dou W, Shi J, Xu Z. Enhancing the production of a novel exopolysaccharide by Bacillus mucilaginosus CGMCC5766 Using Statistical experiment design. Trop J Pharm Res 2013; 12: 711 718.

21. Hudson R, Daniel R. L-glutamate dehydrogenases: distribution, properties and mechanism. Comp Biochem Physiol B Biochem Mol Biol 1993; 106: 767792.

22. Degwert U, Van Hülst $R$, Pape $H$, Herrold R, Beale J, Keller $P$, Lee J, Floss $H$. Studies on the biosynthesis of the alpha-glucosidase inhibitor acarbose: valienamine, a $m-C 7 N$ unit not derived from the shikimate pathway. J Antibiot 1987; 40: 855-861.

23. Inoue S, Nishizawa $Y$, Nagai S. Stimulatory effect of ammonium on streptomycin formation by
Streptomyces griseus growing on a glucose minimal medium. J ferment Technol 1983; 61: 7-12.

24. Okazaki H, Ono H, Yamada K, Beppu T, Arima K. Relationship among cellular fatty acid composition, amino acid uptake and neomycin formation in a mutant strain of Streptomyces fradiae. Agr Biol Chem 1973; 37: 2319-2325.

25. Gonzalez R, Islas L, Obregon A-M, Escalante L, Sanchez S. Gentamicin formation in Micromonospora purpurea: stimulatory effect of ammonium. J Antibiot 1995; 48: 479-483.

26. Hansen K, Angelidaki I, Ahring B. Anaerobic digestion of swine manure: inhibition by ammonia. Water Res 1998; 32: 5-12.

27. Miura S, Dwiarti L, Arimura T, Hoshino M, Tiejun L, Okabe M. Enhanced production of I-lactic acid by ammonia-tolerant mutant strain Rhizopus sp. MK-961196. J Biosci Bioeng 2004; 97: 19-23.

28. Schmidt $D D$, Frommer $W$, Junge $B$, Müller $L$, Wingender W, Truscheil E, Schäfer D. a-Glucosidase inhibitors. Naturwissenschaften 1977; 64: 535-536. 